\title{
On the Crisis of Democracy
}

\author{
José Álvaro Moisés \\ University of São Paulo, São Paulo, Brazil
}

In the last three decades of the 20th century, important political changes occurred in all regions of the world, making the institutions of many existing political systems closer to the ideals of democracy. But as happened in other moments of history, those processes of democratization, even when successful, always occurred through advances and retreats. Thus, contemporary political practices, procedures, and institutions embody democratic ideals only partially. In many nations, in the present, the rule of law, civil, and political rights, and institutional mechanisms for citizens' control of governments remain ineffective or underdeveloped. Thus, a double concern prevails among analysts: on the one hand, the regression to authoritarianism in some countries after the processes of political changes - Russia, Venezuela, Nicaragua, and Turkey being the paradigmatic examples; the emergence of semi-democracies, i.e., hybrid or illiberal regimes, which have provoked a new interest in the study of patterns of institutional design, the critical role of civil society, different political-cultural developments, authoritarian legacies in the context of the new democracies, competitive authoritarianism and new dictatorships. On the other hand, the acknowledgement of intrinsic limits of the historical development of the democratic regime even in the case of old democracies, i.e., the fact that political equality, active citizen participation, and effective control of abuse of power have never been fully realized in practice. This is the general context in which many analysts and part of the public opinion sustain that there is a crisis of democracy. The general diagnosis refers to the decreasing trust in political elites, political parties, parliaments, governments, and to the dissatisfaction with the regime among democrats; it refers also to the weaker and sometimes erratic performance of democratic institutions and particularly to the failure of the representative system. The picture is completed with the growing rates of partisan misalignment, electoral volatility, and declining civic participation. All this seems to indicate that democracy is inconceivable without crisis. This chapter discusses this scenario. The crisis of democracies is examined from a critical perspective, and the main objective is to understand the different dimensions of its nature and its consequences.

Keywords: democratization, crisis, quality of democracy, semi-democracy, illiberal regime, authoritarianism, populism

\section{Introduction}

The world witnessed what seemed to be the advent of a global democratic era between the mid-1970s and the early years of the 21st century. Indeed, after Portugal's Carnation Revolution in 1974, Southern Europe, most of Latin America, Eastern Europe - after the fall of the Berlin Wall in 1989, and also some Asian countries, became democracies. According to international institutions and research projects such as the Freedom House, Polity IV, Varieties of Democracy, and Economist Intelligence Unit, about 60 countries

José Álvaro Moisés, Professor of Political Science, Head of the working group on the Quality of Democracy of the Institute of Advanced Studies, University of São Paulo. 
moved from an authoritarian regime, characterized by the control over politics and society, to a democratic one that had its limits. The outcome, regarded as extraordinary, apparently would continue.

Nevertheless, what Samuel Huntington named in 1991 as the Third Wave of Democratization of the world lasted approximately three decades. In the early 2010s, many analysts began to realize the existence of regressions affecting several cases, like Russia, Venezuela and, more recently, Turkey, which, together with Nicaragua and the Philippines, are paradigmatic examples of the new situation. These were the first signs of what some other authors referred to as semi-democracies, i.e., hybrid regimes or illiberal democracies. In these cases, although the electoral cycles ensue, there are clear restrictions to the actions of the opposition, to the publication of critical information, to the acknowledgment of the rule of law, in addition to the difficulties to control the abuse of power, like corruption, and even the limitation of civil and political rights.

There were also signs of deterioration of the regime in countries with mature democracies, including the limitation of rights, loss of the party identity of many voters, electoral volatility, decrease in political participation, dissatisfaction with the performance of governments, and a growing citizens' mistrust of traditional elites and, even more serious, regarding the performance of democratic institutions like parties and parliaments. This affected directly the legitimacy of the State which, in the context of the globalization effects, often seemed to be giving up relevant decision-making authority for the benefit of the market or of supranational structures. This was also identified as responsible for the loss of income and jobs that reached several social groups worldwide, which, on their turn, felt unprotected in view of globalization and no longer saw themselves as part of the democratic scene.

Today people speak worldwide about the crisis of democracy. The uneasiness or the malaise with the regime is deep-rooted everywhere, not only in the new democracies. This is related mainly to the perception of ordinary people that democracy is no longer successful in delivering what it is designed to; the idea is that the political system does not work as it should, and does not respond to society demands properly, causing the withdrawal or abandonment of politics by citizens. Some analysts even saw signs of the anomy phenomenon in the loss of the sense of basic rules related to the functioning of the political community that is occurring, with corresponding implications both on the legitimacy of the regime and on the necessary subordination of the demos to the law.

Pippa Norris and collaborators named in 1999 the phenomenon of political mistrust of citizens as a sign of emergence of a critical citizenship, which evaluates negatively the performance of republican institutions, but preserves the broad normative support to the democratic regime per se. But neither the ordinary people nor analysts are reassured about the future of democracy. The general feeling today is that the crisis is becoming deeper with no signs of solutions on the horizon. Democracy seems to be trapped by a situation of a systemic crisis, i.e., a situation in which its fundamental institutions and its regular means of functioning either lost or reduced their ability to respond properly to its own challenges and to the citizens' general expectations.

Larry Diamond, among others, has described the situation in 2015 as a democratic recession, i.e., as a world phenomenon which is causing stagnation and regression in the advances of the Third Wave of Democratization, in fact threatening more countries than the known cases of reversal. This recessive outlook of democracy includes the emergence in several regions of the world of the phenomenon of neopopulism, which Jan-Werner Muller and other analysts argued in 2016 that includes criticism of and the objection to the traditional elites, the despise for and the rejection of the political pluralism, and the emotional, moralist, and apologetic representation of the people seen in most cases as an homogeneous entity, without paying attention 
to their differences and diversities. In several cases, the phenomenon of neopopulism caused the abandonment, rejection or the weakening of basic institutions such as parties, parliaments, and the judicial branch. In Eastern Europe, in countries as Poland, the neopopulism and the unconditional defense of Nation's virtues are leading to a clear limitation of the civil rights, even the prohibition to criticize aspects of its history.

\section{Background of the Issue}

A solid theoretical tradition, of which Robert Dahl is one of the most important exponents, defines democracy as a regime essentially based on the peaceful processing of social and political conflicts that are proper of complex and unequal societies. According to him (1989), among many other authors, democracy is the preferred option for the control of violence and the best alternative to manage such conflicts peacefully and to organize the collective life based on competition and on cooperation among actors with different political identities.

This is backed by the notion that the members of the political community are equal to each other and that such equality is achieved to the extent that democratic governments are responsive toward the preferences of their citizens. Such equality comes from the right to choose governments through the vote, but, as Dietrich Rueschemeyer pointed out in 2005, the size of the gap between this ideal and the reality of complex and unequal societies depends always on the commitment between the ruling elites and the demos. In this regard, the uncertainty about the outcomes, as argued by Adam Przeworski in 1991, assumes that this involves tensions regulated and standardized by the rule of law and its enforcement. Thus, the continuity and the stability of the regime is due to the performance of institutions which condition the negotiations and agreements between actors of different and even opposed interests and which are specially designed to achieve these fundamental objectives.

The crisis occurs when part of the relevant actors either resist to or reject in whole or in part this form of functioning of the system and begin to advocate — and, to the extent of their success, to impose - paths of action that violate fundamental democratic principles like freedom and equality. Then the outcome involves clear limits to the freedom of action of opponents, restriction of citizens' rights, and an increasing compromising of the political equality, as shown by recent cases of neopopulism; such developments involve a dangerous process of dismantling the constitutional institutions of the democratic regime (Levtisky \& Ziblatt, 2018).

Examining the antecedents of this process can help to clarify aspects of the current situation. The political transformations of the 1970s and the 1980s, characterized as the Third Wave of Democratization, occurred in the wake of other two previous waves, which on their turn happened after the early democratic breakthroughs initiated with the liberal revolutions of two previous centuries. A long period of significant political advances preceded this late democratization process under the impulse of negotiation among a plurality of actors which sustained different political interests (Marshall, 1967).

This was the period of great stability of the liberal democracies which lasted 40 to 50 years after the end of World War II, which allowed the consolidation of the role of political parties and the expansion of the political participation of the demos. In fact, on the basis of the political commitment of different political forces, a relative decrease of inequalities of the capitalist system and the regulation of the market economy were achieved. This encouraged the introduction of social rights and benefits that had not been considered in the democratization process of the 19th century and the beginning of the 20th century.

Philippe Schmitter argued in 2016 that two driving forces explain the advances of that historic period. On the one hand, the threat coming "from the bottom", during the Cold War, represented by the alternatives 
supported by the so-called popular democracies in terms of new modalities of social and economic equality; the threat was responded by a gigantic political and ideological competition sustained by the liberal democracies. On the other hand, by the surplus "from the top", provided by the extraordinary economic expansion and growth of capitalism, which unlike recent years, gave democratic governments an opportunity to regulate the market economy, to expand social and economic rights, and to consolidate an era of political freedom associated with social achievements.

Under these conditions, democracy has consolidated in about 30 countries in less than half a century. The political life was organized around the role of parties that defined and differentiated themselves based on the opposition between left and right. Without excluding centrist forces, the electoral competition took place between conservative parties - oriented to maintain the status quo and the order-and social democrats, socialists, and communists, who defined themselves in view of the support for class interests and economic and social changes advocated by lower social segments. Instead of electoral volatility, most of the electorate maintained their party identity and the loyalty of their vote; many voters were party members and ensured the continuity of an institutional pattern seen as a facilitator to the integration of political community members in the functioning of the regime. The political trust surveys about that period showed high indices of positive perception by the mass audiences as regards the performance of the democratic institutions during many decades.

\section{The New Face of the Issue}

That situation no longer exists today, the communist threat is gone, the capitalist surplus is over, its appropriation became concentrated, and the globalization weakened the national States which, in the previous stage, had been important players of the democratic advances. The current times correspond to a stage of high concentration of wealth and the increase of inequalities, amplifying the potential conflict of complex and unequal societies. Overall, the capitalist corporations increased their power and their autonomy of action regarding weakened nation States; and unaccountable supranational structures, like the European Union, also encourage such weakening.

In this context, the widespread increase in the uncertainties of the ordinary people regarding their power to participate politically and to influence the choice of public policies is not surprising. The general sentiment is of distance concerning the political and administrative spheres in which the traditional elites isolated themselves to make decisions protected from the pressures and interferences of citizens. Then, more and more the perception of many is that the recent democratic experience made many governments non-responsive toward the preferences of the demos.

The years of democratic success between the 1950s and the 1990s conducted also to other two important roots of the present situation: Firstly, the fact that such successful period of almost 50 years of liberal democracy seems to have led to some kind of obliviousness or lack of sense of a fundamental component of the relations between democracy and capitalism. Whereas the former is driven by an impulse oriented essentially to equality - first the political equality and then the social and economic one-capitalism, on the other hand, implies the creation and increase of inequalities which, recently, were worsened by the effects of internationalization and globalization of economy. This involves a fundamental contradiction that has to be managed politically to ensure on the one hand some minimally indispensable degree of economic and social integration of the ordinary people and, on the other hand, the maintenance and growth of the market economy, 
what leads the issue to an old dilemma: How can democracy face such contradictions and at the same time guarantee its continuity? And what is the role played by the State in this context?

Francis Fukuyama presented in 1989 a controversial diagnosis for what he considered to be the political-ideological basics of this matter and-focusing especially on the implications of the fall of the Berlin Wall in that year, followed by the collapse of the Soviet Union and the democratization of Eastern Europe-he sustained that more than 50 countries had left behind their autocratic regimes and joined the constellation of representative democracies existing in consequence of the Third Wave of Democratization. He emphasized above all that the change consisting in the defeat of the communist alternative worldwide represented the end of history, i.e., the end of the great political and ideological fight opposing the liberal democracies that ensured freedom and competition for power to the popular democracies of the Soviet bloc which, under the control of the communist parties, maintained extremely closed regimes, of authoritarian and even totalitarian characteristics, with strictly formal levels of popular participation, and marked by serious violations of human rights. The gulags of the Stalinist period were one of the paradigmatic examples of the treatment given by these regimes to their dissidents and opponents.

Fukuyama said a history period was then ended, but he apparently did not realize-at least not at that moment - that another history period was beginning, characterized by the huge challenges related to the consolidation of the new democracies, something that went much beyond their formal institutionalization and that required the qualification of the State to meet the promises of the representative democracy in the context of globalization. This related first of all to the establishment of the rule of law, the accomplishment of political equality, the guarantee of political competition and, especially, the consolidation of civil and political rights. But this also implied the implementation of means under which the political equality should operate to qualify citizens to demand social and economic equality, in other words, equal opportunities.

The challenge involved rebuilding the authority of the State in the countries where the crises of authoritarianism had weakened or destroyed its bases; now it was necessary to enable it to perform its duties related to the enforcement of the law, but, at the same time, provide it with the proper means of management and governance suitable to meet the demand of society for efficient public services. This had been one of the great breakthroughs in the previous development of the representative democracies, but it surfaced now as a requirement without which the new democracies would be doomed to failure. What conditions were necessary to meet this requirement?

Dietrich Rueschemeyer answered this question critically in 2005, although admitting that even in its minimal and more formal kinds, representative democracy always creates an amount of political equality arising from the right to vote held by ordinary people. However, according to him, the problem appears on the limits of representative democracy to face the fact that the relatively independent sphere in which political decisions are made - protected by the free competition among political forces and by the guarantee of freedom of speech and of association - neither neutralizes nor eliminates the weight of unequal social and economic structures arising from capitalism.

Wealth, differences in possessions, prestige, and access to power resources have repercussions on the political competition and affect the principle of political equality. And the relationship between money and politics does not reach only the funding of electoral campaigns, but operates as a permanent and extremely important condition of the asymmetrical capacity of action by the different actors of contemporary democratic politics. While ordinary people rarely have time enough to participate and to access the critical information 
about what is at stake in politics, the richer have time, contacts, and better resources to be informed and to press the decision-making processes that affect the political community as a whole.

This is one of the most critical characteristic of the political equality. The issue involves fairness in electoral competition and choice of governments, but also access to the constitutional prerogative of ordinary people to run for government if they so wish; the question however remains: What is the actual and effective influence of ordinary citizens to the definition of public policies?

The dilemma arising from such situation consists in knowing to what extent the institutional structures - the electoral system, parties, parliaments and the judicial branch-and other means of functioning of democracy are sufficient to account for the asymmetries existing in an increasingly unequal world. The issue is to what extent the freedom guaranteed by the really existing democracies authorizes the interference of ordinary citizens in matters related to the implications of the inequality. In other words, the question is if the equality of rights enjoyed by the members of the political community, conditioned by the status of socially and economically unequal actors, suffices to guarantee the participation of ordinary people in the functioning of the regime, ensuring that their interests, preferences, and aspirations are taken into account by parties, parliaments, the judicial branch and elected governments.

Giovanni Sartori discussed this dilemma when reflecting on the approximations and the differences of the liberal and republican traditions of democracy (2017), and argued that this political regime involves a dialectic dispute between what he named, on the one part, demos-protection, i.e., the freedom and the protection ensured to the members of the political community against private and State powers; and, on the other part, demos-empowerment of the political community members, that is, the potential power of ordinary people, resulting from the concept of popular sovereignty, to control, oversee, and monitor the ruling elites, in addition to the act of electing them.

Although it is evident that freedom is a value per se, it is also a condition necessary for the empowerment of citizens, i.e., of the sphere in which they act with autonomy and independence among each other and in relation to the power of the State. Sartori referred to this notion to suggest that in democracy voters are not only the rulers, who authorize, who can rule on their behalf for defined terms in office and under strict rules, but rather, who has the power to monitor, oversee, and demand responsibility of the government and, thus, control and/or punish abuses of power.

As it is evident, the emphasis here is on the role of the democratic institutions, whose functioning is a path that can make room, or not to defend the interests of citizens and to fulfill their preferences. However, the crisis of recent years focusing at the same time on the contradictory advances of the Third Wave of Democratization worldwide and the achievements that seemed to define the nature of mature democracies, questions the effectiveness of the regime's performance. What changes characterize the emergence of that new scenario that apparently threatens achievements deemed as consolidated until recently?

\section{An Eye on the Measures of the Issue}

With the purpose of giving some answers to this question, the next parts of this chapter are backed on partial results of the application of the 2017 Democracy Index of the Economist Intelligence Unit (EIU). The Index provides a general overview of the state of democracy worldwide for 165 independent states. It covers almost the entire population of the world and the vast majority of the world's states. The main advantage of using this Index is the fact that it is based on the interrelation of five crucial variables which are not always 
taken all together by other similar indices as the one of the Freedom House: electoral process and pluralism; civil liberties; the functioning of government; political participation; and political culture. The objective of considering the theoretical significance of the interaction among variables such as political processes, institutions, and political values is evident in this case. Based on its scores in a range of indicators within these categories, each country is then classified as one of four types of regime: full democracy; flawed democracy; hybrid regime; and authoritarian regime.

What is at issue is the quality of democracy (O'Donnell, Cullell, \& Iazzetta, 2004; Diamond \& Morlino, 2005). To measure and evaluate the qualities of a democratic experience is something that depends in the first place on the existence of a democratic regime. Most analysts seem to agree that, at a minimum, the fundamental features of a democracy include government based on majority rule and the consent of the governed; the existence of free and fair elections; the protection of minority rights; and respect for basic human rights. Democracy therefore presupposes equality before the law, due process of law and political pluralism.

Nevertheless, consensus on how to measure democracy is not an easy task (Munck, 2009). This is due to the fact that democracy is a contested concept. Aristotle wrote of democratic Greek city-states where citizens were supposed to participate in self-government, but these polities excluded women and slaves from citizenship and political participation. Rousseau, Montesquieu, and more recently Bobbio and Sartori, among others, have wrote of the democratic regime as the one that allows members of the political community to live under a regime of laws, governed by an institutional structure that guarantees basic individual and collective liberties and rights, and hence, provides freedom from domination. Yet, the recent global expansion of regimes claiming to be democratic has led scholars to revise the long accepted definitions that emphasized competitive elections, civil, and political rights, and a market economy (Munck \& Mantilla, 2013).

Procedural definitions are considered to be the most empirically-solid reference to define the democratic regime, understood as an empirical phenomenon infused by the ideals of freedom and equality (Schumpter, 1961). But even so, it is not clear whether reference to these basic features is sufficient for a satisfactory concept of democracy. In fact, some authors question how far the definition may need to be widened. While some insist that democracy is a dichotomous concept — a polity would be either democratic or not —others, as the EIU analysts in 2017, correctly argue that the adequate measures should adhere to a continuous concept, with the possibility of varying degrees of democracy (Coppedge et al., 2011).

"Democracy is more than the sum of its institutions", they say, and that is the reason why the regime should be seen as a set of principles and practices that institutionalize and protect freedom. This contrasts with the idea of many, for whom elections are the cornerstone of the regime. To hold free and fair competitive elections, in the context of related aspects of political freedom, seems to be the sine qua non of their definitions. But other contemporary anti-minimalist definitions of the democratic regime also consider civil liberties, accountability and the control of power abuse — and its corresponding values and political culture — to be basic components of the liberal democracy; accordingly, the protection of basic human rights, including access to justice and political participation, is widely embodied in democratic constitutions in different areas of the world (Pinto, Souza, \& Magalhães, 2013; Moisés, 2015).

Democratic electoral processes in different parts of the world have in fact shown that they do not necessarily guarantee the establishment of political systems capable of ensuring fundamental principles such as the rule of law, respect for citizens' civil, political, and social rights, and the oversight and control of governments. Once the new regime has been established, despite signaling that undemocratic alternatives have 
been overcome and that in the future the choice of who governs must be subject to the principle of popular sovereignty, elections alone do not guarantee that electoral democracies will meet the minimum criteria of democracy. Authoritarian regimes may persist and indeed shore up their legitimacy through elections. In Eastern Europe, Latin America, Asia, and Africa, some polities that have adopted competitive elections coexist sometimes with governments that are not completely committed to the principles of equality before the law, political inclusion, and control over and punishment of corruption. In many cases, parties and politicians that misappropriate public funds to accomplish private objectives-and function and operate without any mechanisms of vertical, social, and horizontal accountability-came to power through popular election (Mainwaring \& Welna, 2003).

In this respect, the EIU's Democratic Index is a valuable alternative to measure the relevant dimensions of the situation. It is based on the view that measures of democracy, which reflect the state of political freedoms and civil liberties only - as it is done by the Freedom House, among others - do not necessarily encompass the features related to how substantive democracy is. Political participation and the functioning of government, for instance, are not always taken into account by some measurements of the quality of democracy either. On the contrary, the EIU's Democratic Index is based on the analytic interaction of five categories: electoral process and pluralism; civil liberties; the functioning of government; political participation; and political culture. Those categories are supposed to be interrelated and to form a coherent conceptual whole, which is fundamental to measure the quality of democracy (Diamond \& Morlino, 2005).

Democracies are seen then as political systems based on the majority rule, but this is not necessarily or always democratic; majority rule should be combined with guarantees of individual human rights and the rights of minorities. Valuable measures should also include aspects of the minimum quality of functioning of government "because - as the EIU's analysts sustain - if democratically based decisions cannot be or are not implemented, the concept of democracy will not be seen as very meaningful". A democratic political culture is also viewed as crucial for the legitimacy and the sustainability of the system (Moisés, 2011). "A culture of passivity and apathy is not consistent with democracy". Finally, as argued by them, participation is also an essential component, while abstention is detrimental to the democratic regime. "Citizens are free to express their dissatisfaction by not participating, but a healthy democracy is supposed to flourish when citizens take part in the public debate, elect representatives, join political parties and pay attention to the government' performance"; without it democracy becomes the sole territory of powerful private groups, and is no longer the space of collective decisions. The idea then is that those multidimensional factors should be taken all together to adequately measure the quality of the democratic regime.

\section{On the State of Democracy in the World}

From such standpoint, the data collected by the EIU for 2017 enable us to make a general first assessment of the state of democracy in the world today. In accordance with the results shown in Table 1, a bit less than one-half of 167 countries around the world are considered to be democracies today, or 76. Full democracies are 19 , or only $11.4 \%$ of the countries studied, while 57 , or $34.1 \%$, are rated as flawed democracies. Of the remaining 91 countries in the index, $31.1 \%$ (52) are said to be authoritarian, while $23.4 \%$ (39) are considered to be hybrid regimes.

The Figure 1 suggests that relevant questions are involved in the debate. The criteria used by different international institutions to construct the proposed indices of democracy and authoritarianism are under 
controversy, but the EIU's index provides a helpful empirical point of departure to analyze the multiple factors that are deepening or worsening the quality of democracy in the present. The data used below approach the world and the Latin American situation in the present days.

Table 1

Democracy Index 2017, by Regime Type

\begin{tabular}{llll}
\hline No. of countries & & \% of countries & \% of world population \\
\hline Full democracies & 19 & 11.4 & 4.5 \\
Flawed democracies & 57 & 34.1 & 44.8 \\
Hybrid regimes & 39 & 23.4 & 16.7 \\
Authoritarian regimes & 52 & 31.1 & 34.0 \\
\hline
\end{tabular}

Notes. "World" population refers to the total population of the 167 countries covered by the Index. Since this excludes only microstates, this is nearly equal to the entire estimated world population. Source: The Economist Intelligence Unit.

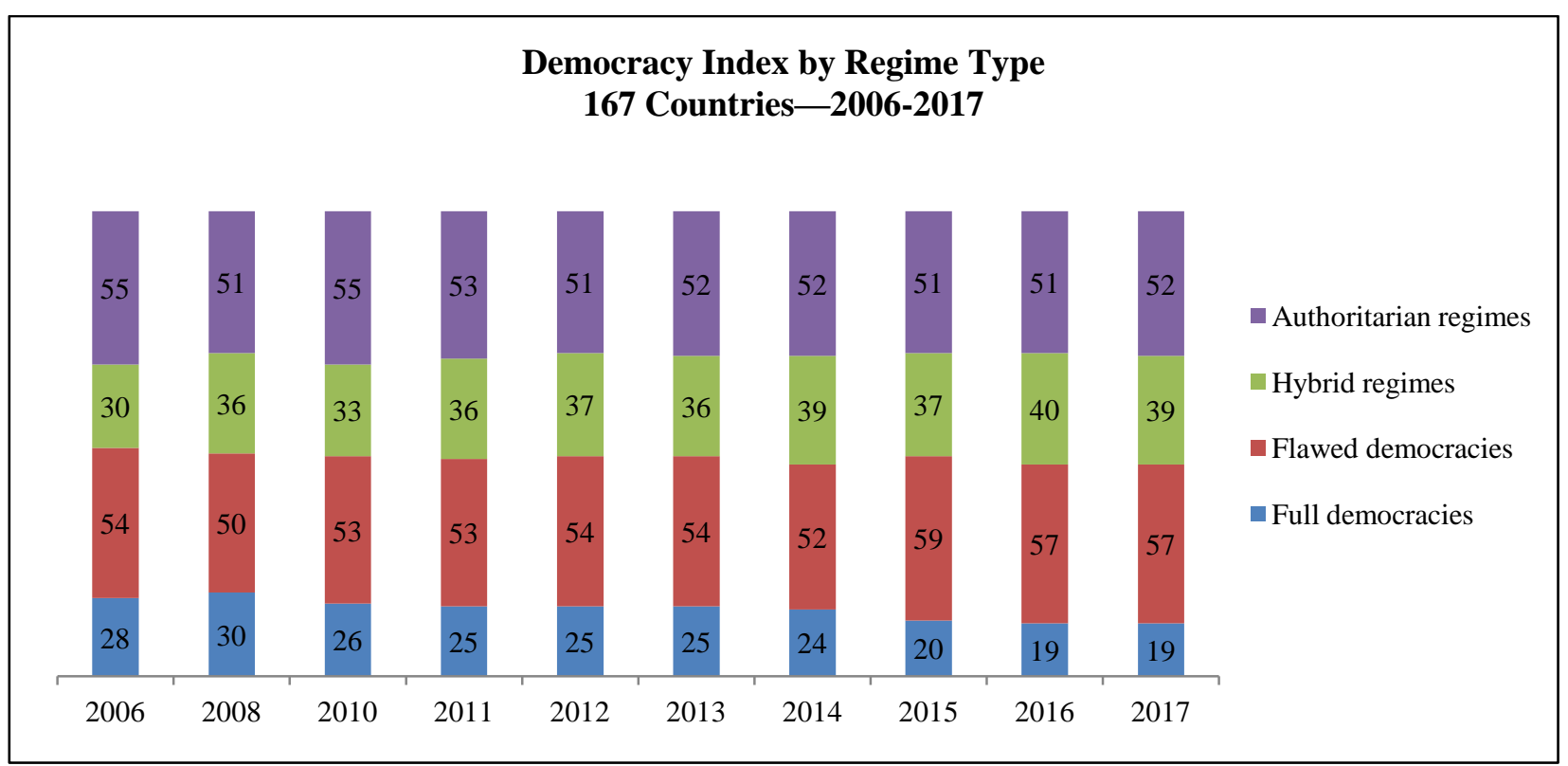

Figure 1. Democracy Index by regime type 167 countries-2006-2017.

According to the EIU's analysis, the average global score of the Democracy Index fell from 5.52 in 2016 to 5.48 in 2017 , on a scale of 0 to 10 . Some 89 countries experienced a decline in their total score compared with 2016, more than three times as many as the countries that recorded an improvement (27), the worst performance since 2010-2011 in the aftermath of the global economic and financial crisis. The other 51 countries stagnated, as their scores remained unchanged compared with the previous year. These data show that $49.3 \%$ of the world's population lives in a democracy of some sort, although only $4.5 \%$ lives in a full democracy - down from 8.9\% in 2015, as a result of the US being reclassified as a flawed democracy in 2016. On the other hand, nearly one-third of the world's population lives under authoritarian regimes.

In other words, the EIU's Democracy Index shows that in 2017, 76 out of the 167 countries covered by the model - or $45.5 \%$ of all countries - can be considered to be democracies. The number of full democracies remained at 19 in 2017, the same as in 2016, when the total declined from 20 in 2015. Of the remaining 91 countries in the index, 52 are authoritarian and 39 are classified as hybrid regimes. The data also show that between 2006 and 2017, the number of full democracies decreased from 28 to 19, and such difference of 9 
cases was redistributed among the flawed democracies and the hybrid regimes. However, the sum of cases classified as hybrid regimes was also affected by the redistribution of cases until then classified as authoritarian. Indeed, while the total of countries classified as authoritarian was 55 in 2006, such index fell to 52 in 2017, whereas the sum of cases of hybrid regimes grew from 30 in 2006 to 39 in 2017. Therefore, the results indicate a pattern of changes meaning clear regressions and retreats, but also small advances of democracy.

How to explain the deterioration in the practice of democracies all over the world in recent years? Agreeing with Larry Diamond's diagnosis, according to which the world is going through a democratic recession, the EIU's analysts concluded that this has been particularly the case of some of the oldest democracies in the world - whose regression since 2006 reflects particularly the situation of the Western and Eastern European countries. The main characteristics of this democracy recession are said to include: declining popular participation in elections and politics in general; weaknesses in the functioning of government; declining trust in institutions; dwindling appeal of mainstream representative parties; growing influence of unelected, unaccountable institutions and expert bodies; widening gap between political elites and electorates; decline in media freedoms; erosion of civil liberties, including curbs on free speech. All factors mentioned show that the issues related to the functions both of accountability and of responsiveness are affected, downgrading the quality of democracy.

Indeed, from this set of causal factors, considering the specific situation of countries of the geographic areas mentioned, what stands out firstly is the downfall of parties and parliaments as political bodies contributing to the participation and influence of voters. The decline in the quality of democracy have caused the growth of support for anti-establishment and reformist parties in Western Europe, both on the left and on the right. The most emblematic cases are the ones of Italy, Spain, and France, where the crisis of the traditional parties was expressed in the misalignment of many voters, in the mistrust of these parties and their leaders, and in the emergence of alternatives like the Podemos and Ciudadanos in Spain, the Movimento 5 Stelle and several far-right parties in Italy, and the En Marche! in France, with the rise of Emmanuel Macron. In the three cases, the emergence of those alternatives expanded the crisis of the traditional parties and strengthened the tendency of loss of its leading role in the formation of governments, as occurred recently in France and in Italy. Similar symptoms also reached Germany, although more mildly.

In some of these cases, the problem of the traditional social democratic and communist parties' failure to address the concerns and insecurities of younger and working-class voters remains unresolved. "This has been the basis of the anti-establishment sentiments about the future, leading some parties to adopt illiberal stances in order to counter the rise of populism", according to the EIU. The changes of voters as regards the parties were accompanied also by the increase in the levels of mistrust concerning parliaments and, in some cases, by the appearance of nationalist leaders who introduced programs restricting civil rights, like Poland. In this case, the institutional deficit represented by such changes leaves part of the political community without dependable instruments for them to intervene and defend their interests, what evidently aggravates power asymmetries.

Secondly, there is the reality of supranational bodies and institutions that made the decision makers dangerously distant from the ordinary citizens and created arenas in which important issues are entrusted to non-elected bureaucratic agencies, which operate far from the eyes of the public, and that cannot be reached by control mechanisms. The most known examples are those of the bureaucracy of the European Union, especially the case of the European Central Bank which, in recent cases of crisis in community member countries-like Greece and Portugal—was target of objections and harsh criticisms from voters of these countries. 
Finally, the data also show that in several of those countries, but also in others like the USA, there were erosions in the field of civil liberties and of the freedom of speech under the justification of fighting terrorism and immigrations. All of this worsened the levels of mistrust of citizens concerning politicians and democratic institutions. Consequently, the sentiment among large segments of the public opinion is that the reserves of representative democracy to face the crisis are running out, without envisaging alternative resources to fight the challenges of the present.

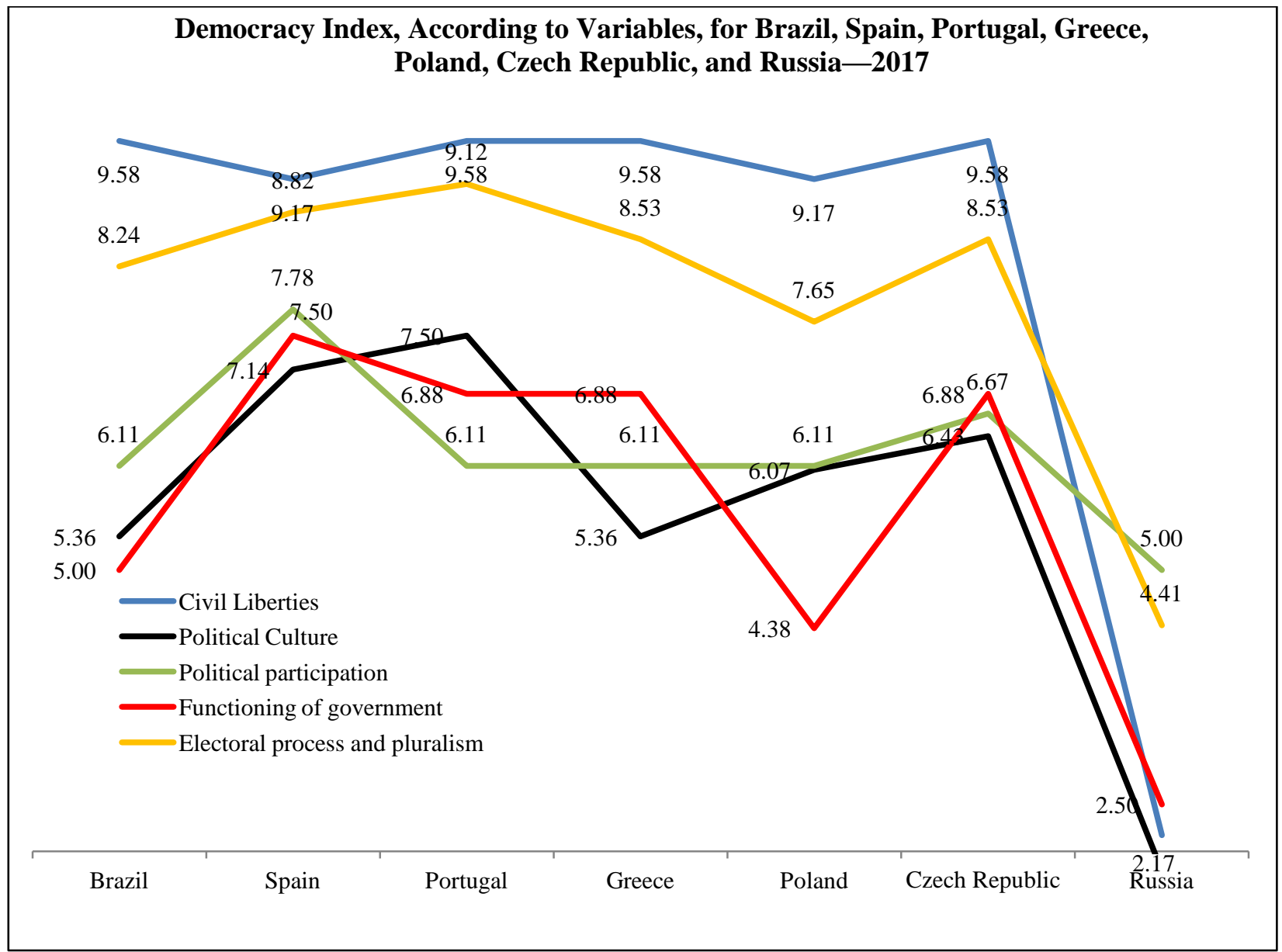

Figure 2. Democracy Index, according to variables, for Brazil, Spain, Portugal, Greece, Poland, Czech Republic, and Russia-2017.

A mere comparison of the performance of the variables explaining the model adopted by the EIU for some countries that became democracies in the last 30 to 40 years shows how-although the crisis of democracy in recent years was due mostly to the erosion of civil and political rights, to the non-existence of a culture of adhesion to the democratic regime, and to the poor functioning of the government in countries like Poland, Czech Republic, and Russia - the cases of Spain and Portugal, differently, are in a more favorable position precisely because their indicators of civil rights, political participation, political culture, and functioning of the government are better, while Greece remains in an intermediate position between those two groups. As for Brazil, whose democratization process began 10 years after the changes witnessed in Southern Europe, although cannot be compared to the situation of Russia, Czech Republic, and Poland, it clearly has a position 
lower than Spain and Portugal, especially concerning the functioning of the government and adhesion to values of the political culture. The issues of functioning of the democratic governance in Brazil led to the impeachment of the president elected in 2014 and, more recently, accusations of corruption involving several parties led to the imprisonment of politicians from different political and ideological positions. It is evident in those cases that the differences of the indices assessing the different variables are also indicators of the distinct modes of the relations between citizens and State structures in the countries examined.

\section{On the State of Democracy in Latin America}

The information and the data available also allow for a specific examination of the situation in Latin America as a whole. Figure 3 below indicates a slight decline of the general index measuring democracy between 2006 and 2017 in the area, i.e., a fall from 6.37 to 6.26 in the last year of checking. This is not a dramatic drop, unlike other parts of the world, but it indicates that the democratic regime is not completely consolidated in this continent yet, with the measurement indices presenting frequent oscillations. Indeed, as we can see in the figure, the Democracy Index grows in 2008, oscillates downwards between 2011 and 2015, and then its fall increases until 2017. Nevertheless, as the EIU's analysts have written, this region remains the most democratic in the developing world, while it scores above the global average for electoral process and pluralism; this confirms the political regime's classification of the majority countries of the continent as electoral democracies. But the region's performance is worse in other categories: Latin America's average score is only slightly ahead of the global average for functioning of government as well as for political participation, reflecting the region's issues with abuse of power, systemic corruption, organized crime, and low levels of political engagement. All those factors affect profoundly the political conditions of citizen participation in Latin American democracies.

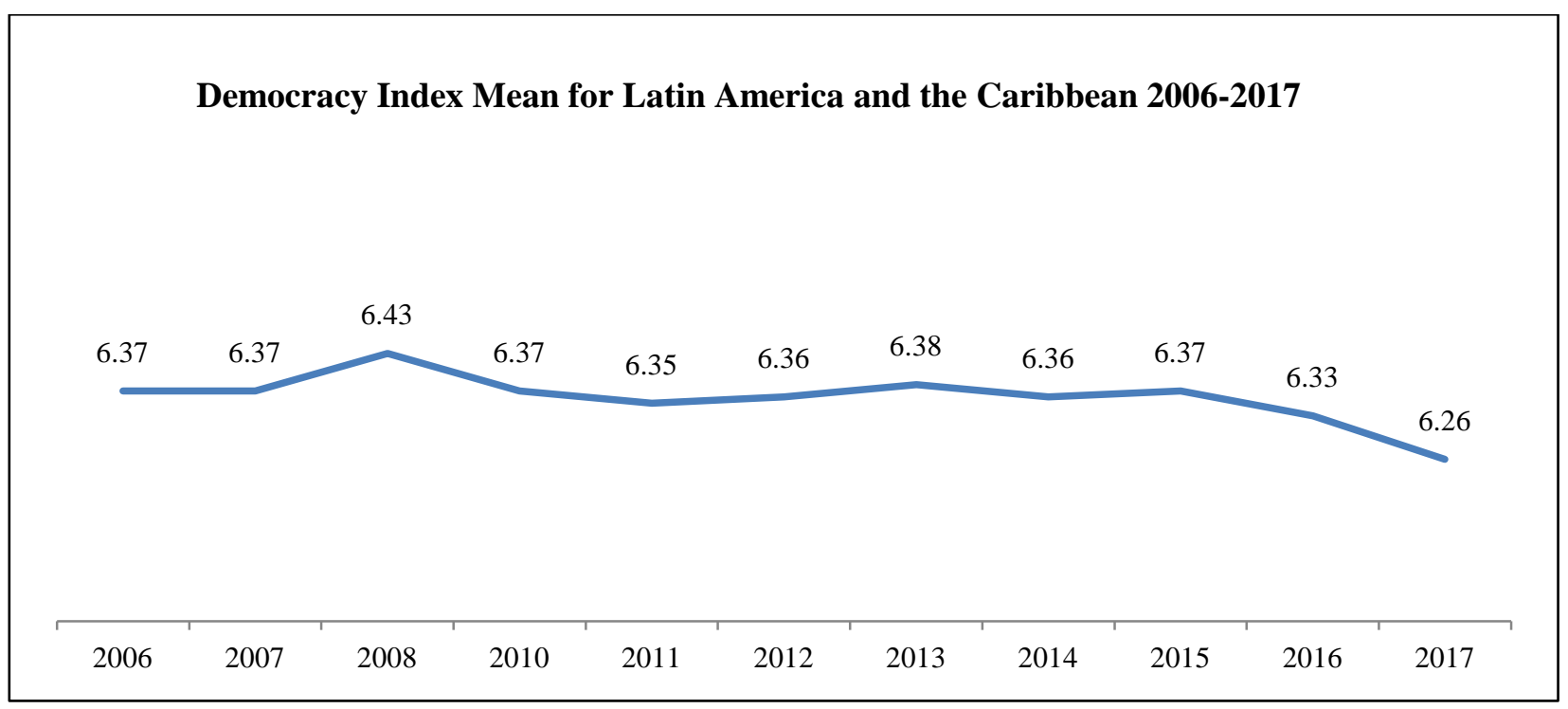

Figure 3. Democracy Index Mean for Latin America and the Caribbean 2006-2017.

Indeed, the data show a slight deterioration of the general picture of democracy in the area, since while between 2006 and 2017 the cases of authoritarian regimes doubled from 1 to 2 cases - especially with the change of the situation in Venezuela, which now joins Cuba in that classification - the number of full 
democracies fell from 2 to 1 , with a slight change in the situation of Costa Rica, with problems in the functioning of parties. On the other hand, the index related to the flawed democracies had some oscillation, growing from 17 in 2006 to 18 in 2008, but falling to 13 in 2014 and rising again to 16 in 2017. Finally, in the case of hybrid regimes, the index changed from 4 in 2006 to 7 in 2011/2012, and fell to 5 in 2017. Concerning Cuba, the oldest case of an authoritarian regime in the region, such classification was confirmed again with the recent change in the top government positions, with the rise of Miguel Díaz-Canel to the leadership of his country, performed through a selection process that excluded - by definition - the participation of any opposition forces (which, however, do not exist in view of the political repression conditions maintained by the government).

The EIU's analysts have also drawn attention to the fact that Latin American societies are below the global average for political culture, an important factor of the processes of democratic regime consolidation, revealing low levels of popular confidence in republican institutions, political participation and adherence to the regime. In fact, according to the consortium Latinobarómetro, public adherence to democracy has been declining since the beginning of data collection in 1995, falling to 53\% in 2017, a narrow majority, while other $30 \%$ of respondents say they might prefer an authoritarian regime. Surveys conducted by the Latin American Public Opinion Project-LAPOP, from the Vanderbilt University, performed in 2016/2017, confirmed such tendency. As it is evident, the mistrust of citizens as regards the regime and its institutions do not favor the possibilities of democratic activism and, following this path, the defense of the interests of popular segments.

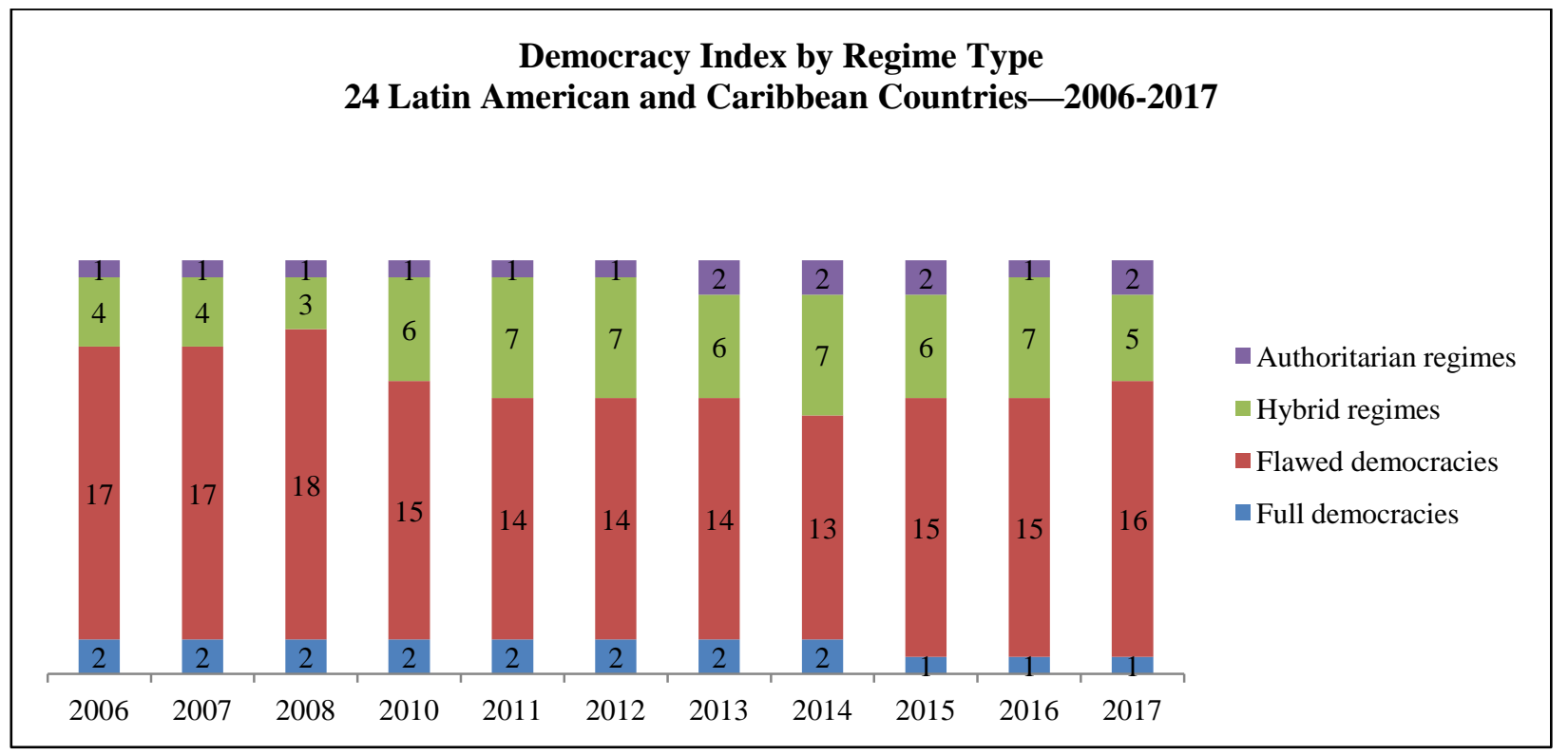

Figure 4. Democracy Index by regime type: 24 Latin American and Caribbean Countries-2006-2017.

Considering the Latin America continent as a whole, the majority of countries showed minor changes in their overall scores in 2017, but two countries have gone through more substantial changes: In the first case, Ecuador moved from a classification as hybrid regime to a flawed democracy, reflecting decisions made by its new president, Lenín Moreno, to implement measures against the attempts of democratic dismantling of the constitutional institutions taken by his predecessor, Rafael Correa, particularly with respect to freedom of the press and the combat of corruption. Venezuela, however, which is the second case, no longer ranks as a hybrid 
regime, but as an authoritarian one, joining Cuba in that category. The region then counts one full democracy, Uruguay, 16 flawed democracies, 5 hybrid, and 2 authoritarian regimes.

In recent decades, some Latin American leaders have acted to limit citizens' rights and freedom of the press. The revelation of continued corruption scandals in several countries has increased citizens' skepticism about politicians and also politics as such. Indeed, the fight against the abuse of power and especially against corruption had a huge highlight in the examination of the political situation of that region in recent years. Based on investigations of the Operation Car Wash in Brazil—which has exposed malfeasance between politicians and large constructing companies of the country, involving kickbacks in return for government contracts and other political favors, the accusations and investigations of corrupt practices by Odebrecht, one of Brazil's major engineering companies at the center of the scandal, was felt across the region due to its operations over decades in several countries.

While in Brazil president Michel Temer succeeded to avoid a trial over corruption charges in 2017 as his allies in Congress voted to block two separate requests by the prosecutor-general to open a trial at the Supreme Court, the allegations cost his job to the Peruvian president, Pedro Pablo Kuczynski, at the beginning of 2017, and led to the forced removal from office of the Ecuadorian vice-president, Jorge Glas. Investigations of Odebrecht evidenced the participation of politicians in corrupt practices not only of Brazil, but also Peru, Colombia, Panama, the Dominican Republic, and elsewhere, and revealed that the firm paid bribes to many of them in recent years. In all those countries - and particularly in Brazil-negative scores of the functioning of government reflected the adoption of anti-democratic norms and were severely rejected by the public opinion. Although the fight against corruption shows that the institutions of control are becoming consolidated in this region, the continuation of the perpetration of crimes of such nature for long periods of time suggests that only recently the mechanisms of the horizontal accountability system have been operating more efficiently. In general, the deterioration of democracy in the region, like what occurred in other parts of the world, showed an increasing rejection of the democratic institutions, according to a recent survey conducted by the Latin American Public Opinion Project (LAPOP), of the Vanderbilt University. In this regard, it must be mentioned that the incumbents tried to extend their time in office beyond the limits of established constitutional terms in Bolivia, Ecuador, and Venezuela in recent years.

The quality of democratic governance is also under risk in some contexts, as it has been exacerbated by economic slowdown and persistent criminal violence in some countries. For example, in Brazil more than 60,000 people are murdered each year, and recently a human rights activist, Marielle Franco, who was also an elected council member for the Rio de Janeiro city, was murdered by criminals supposedly associated with authoritarian opponents of the issue. In Venezuela - the EIU's report states, the scarcity of basic goods led to violent street protests repressed by Maduro's regime, and this action sparked renewed street protests. The police responded by cracking down on protestors, resulting in numerous deaths. Also in Mexico, Bolivia, and Central America, the violence combined with distrust in law enforcement led to the execution of suspected criminals without trial, undermining the authority of the State and its legitimate monopoly of the use of force. In Guatemala, the president Jimmy Morales ignite a political crisis by trying to expel the head of the UN-backed International Commission against Impunity, as he started to investigate allegations that a drug-trafficking cartel had funded Mr. Morales's presidential campaign. The Supreme Court vetoed the expulsion, but Congress upheld Mr. Morales's presidential immunity. The presidential election in Honduras, in November 2017, is also said to have had serious irregularities in the voting process, and in Nicaragua, the 
ruling Frente Sandinista de Liberación Nacional had a sweeping victory at the municipal elections in 2017, which the Organization of American States denounced as illegal and unfair.

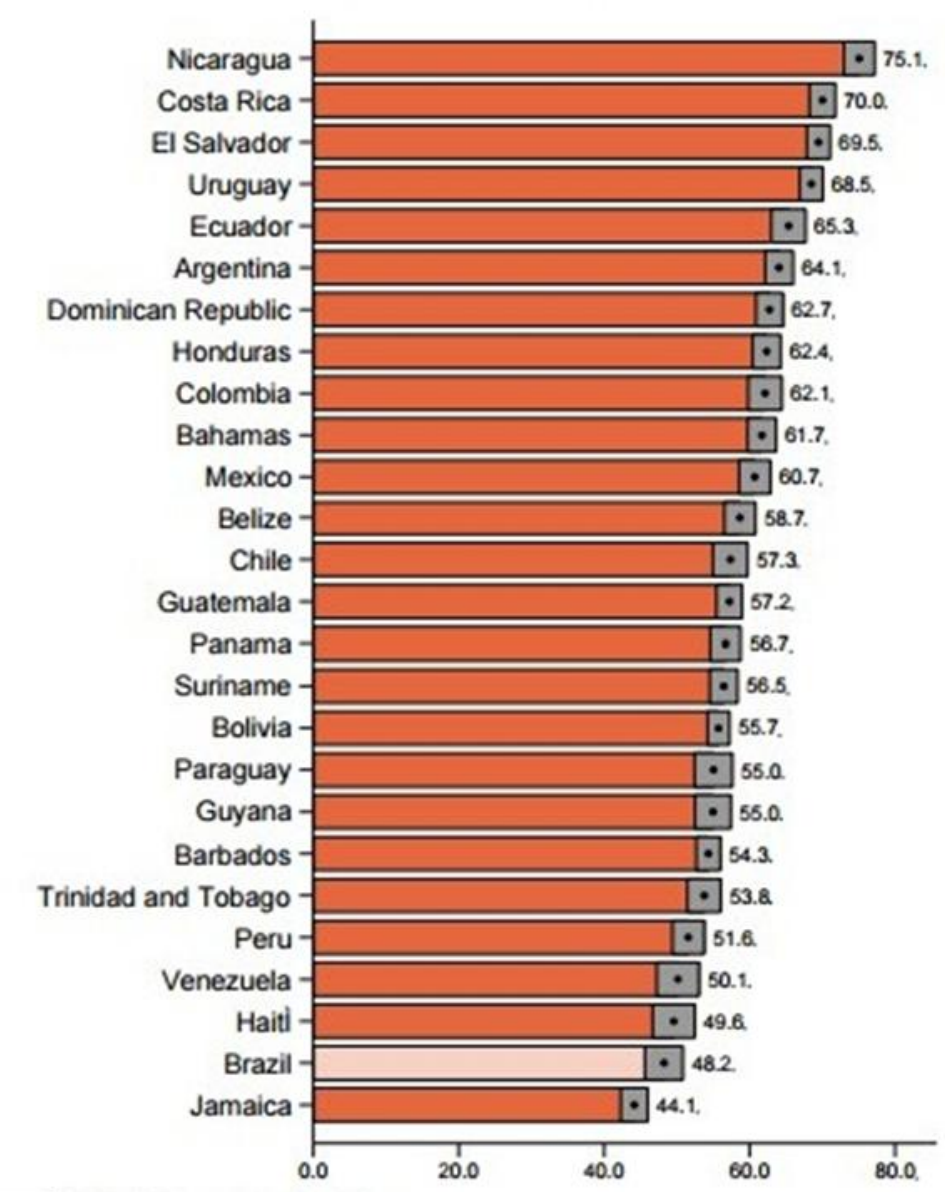

95\% Confidence Interval (based on the drawing effects)

Fonte: Ф.AmericasBarometer, LAPOP, 2014; Merged Rev3.0_W.

Figure 5. Average level of respect for political institutions, 2014-2015.

A partial comparison among some countries of this region shows the existence of three more significant blocks of democratic experience in recent years: In the first case, countries like Uruguay, Costa Rica, and Chile, whose indices for the different explanatory variables adopted for measurement by the EIU are very similar, such as especially the indicators of civil liberties and of political culture. However, the indices show slight oscillations as regards the indicators of political participation and functioning of the government, but those countries stand out in the group of this region because they are more democratic. Both the longevity of the democratic experience and the greater and more deep-rooted tradition of democratic values are important in this case, without disregarding the fact that these are smaller countries, what seems to favor the capacity of the State to fight the challenges of governability.

The second group consists of Brazil, Argentina, and Mexico - countries that are much larger and more populated, with the latter ranking lower as regards the general index of democracy. In this group, the variables whose behavior is more similar refer to the political participation and to the functioning of the government, while 
the indicators of civil liberties, political culture, and electoral processes and pluralism have differences that are more significant. Brazil ranks better as regards civil liberties, while Mexico has better scores for political participation, and Argentina, the country with the longest democratic tradition, has better performance in political culture. However, what draws our attention is that the three countries of this group have lower indices concerning the functioning of the government. This relates to the functions of accountability and responsiveness of governments, what affects the quality of democracy.

The last group of this comparative chart refers to Ecuador, Bolivia, and Venezuela, showing a huge difference for all the variables in relation to the two previous groups of countries. Venezuela is almost an isolated, unique case, in view of the lower indices in important variables like civil liberties, political culture and functioning of the government. In this regard, the situation of recent years revealed a quite decayed picture because of prohibition and repression actions performed by the Nicolas Maduro administration against the political opposition; only regarding political participation the performance of Venezuela is better than the other two countries, since, unlike Cuba - the second country classified as authoritarian in the region, Maduro's regime still preserves a certain degree of electoral competition between government and opposition forces, notwithstanding the evident restrictions to the functioning of the latter. Nevertheless, the situation of Venezuela became even worse recently because of the repression acts by the security forces against anti-government demonstrators. Finally, the low indicators of political culture and functioning of the government in Ecuador and Bolivia are manifest. In both cases, the administrations of Correa and Morales were responsible for initiatives and actions that dismantled the constitutional institutions, intended to both interfere in and limit the courts and parliament functions, with attempts to create rules making reelection easier. In Bolivia, in fact, President Evo Morales overrode the result of a 2016 referendum which rejected an extension of presidential term limits and made the Supreme Court - dominated by loyalists - declare him eligible for a fourth presidential run in 2019.

Finally, the existence of different groups of countries becomes more evident when you consider the comparison for the whole of the continent, through a chart including aggregate data about the behavior of all the variables of the model for all the countries. In first place, Uruguay, Costa Rica, and Chile, among them there are cases of full and flawed democracies, with better performance in nearly all the variables, with exception of political participation for Uruguay and Chile, and political culture for the three cases. Argentina, Brazil, Colombia, Peru, and Panama constitute the next group, with flawed democracies and hybrid regimes, highlighting in this case the performances related to civil liberties, electoral process and pluralism-the fundamental guarantees of the democratic regime. However, the greatest oscillations relate to the functioning of government, which is critical in almost all the countries, and political culture. We can identify then a group consisting of Peru, El Salvador, and Paraguay, whose performance in nearly all the variables is lower, especially political culture and political participation. Finally, there is a group including most of the hybrid regimes, flawed democracies and authoritarian regimes, namely, Ecuador, Guatemala, Bolivia, Honduras, Nicaragua, and Venezuela. Nearly all the variables show lower indices in comparison with the other cases, but what draws our attention is especially the cases of Nicaragua and Venezuela as regards the electoral process and pluralism, functioning of government and civil liberties.

The general scenario of Latin America suggests that although the losses of achievements proper of the democratic consolidation process are lower than in other parties of the world, there is still much to be done in order to ensure regimes of freedom coexisting with the principles guaranteeing the rule of law, the valorization of the republican institutions, and the mechanisms to monitor, oversee, and control abuses of power. 
Democracy Index (Variables) for Uruguay, Brazil, Bolivia,
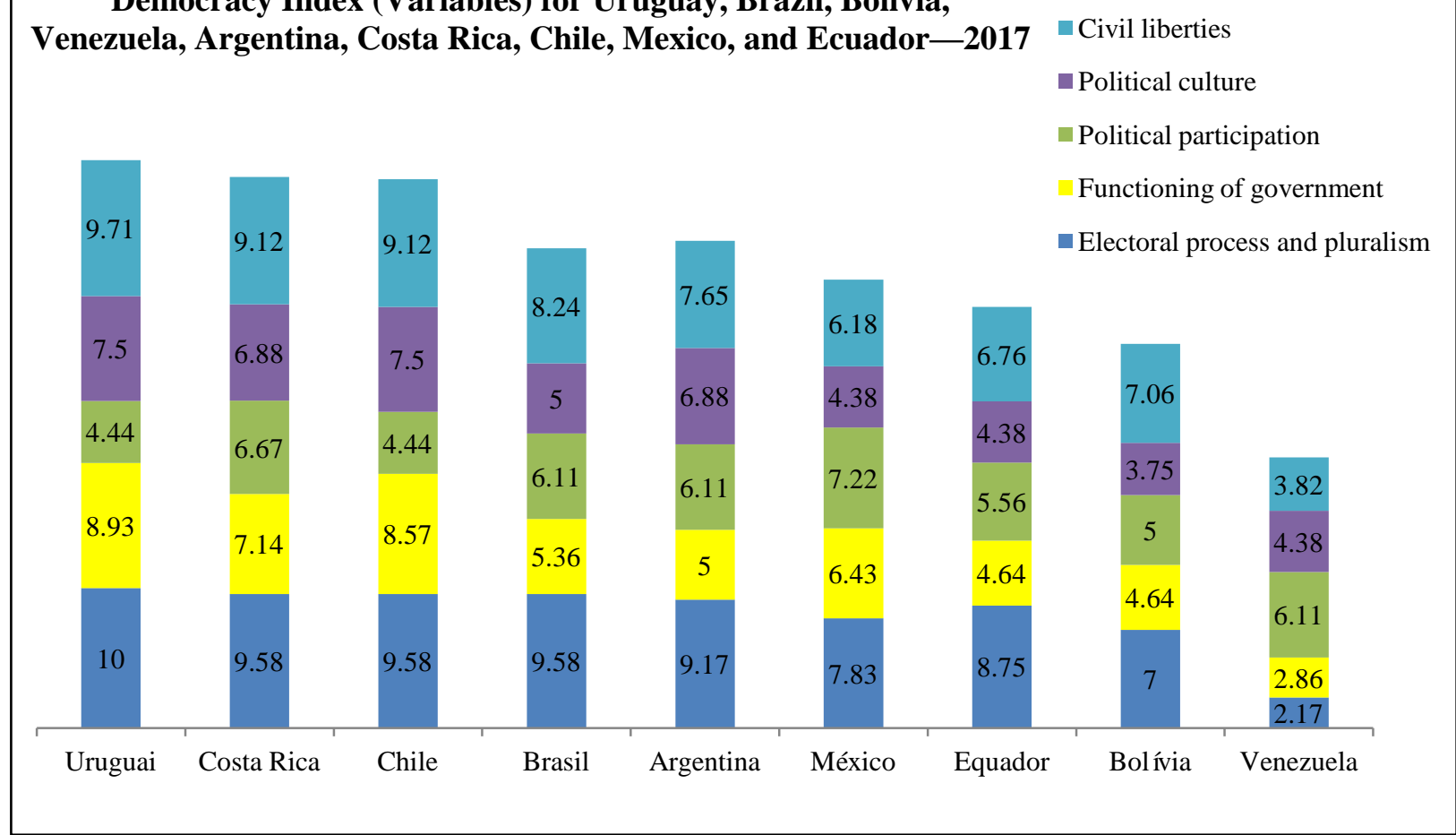

Figure 6. Democracy Index (variables) for Uruguay, Brazil, Bolivia, Venezuela, Argentina, Costa Rica, Chile, Mexico, and Ecuador-2017.

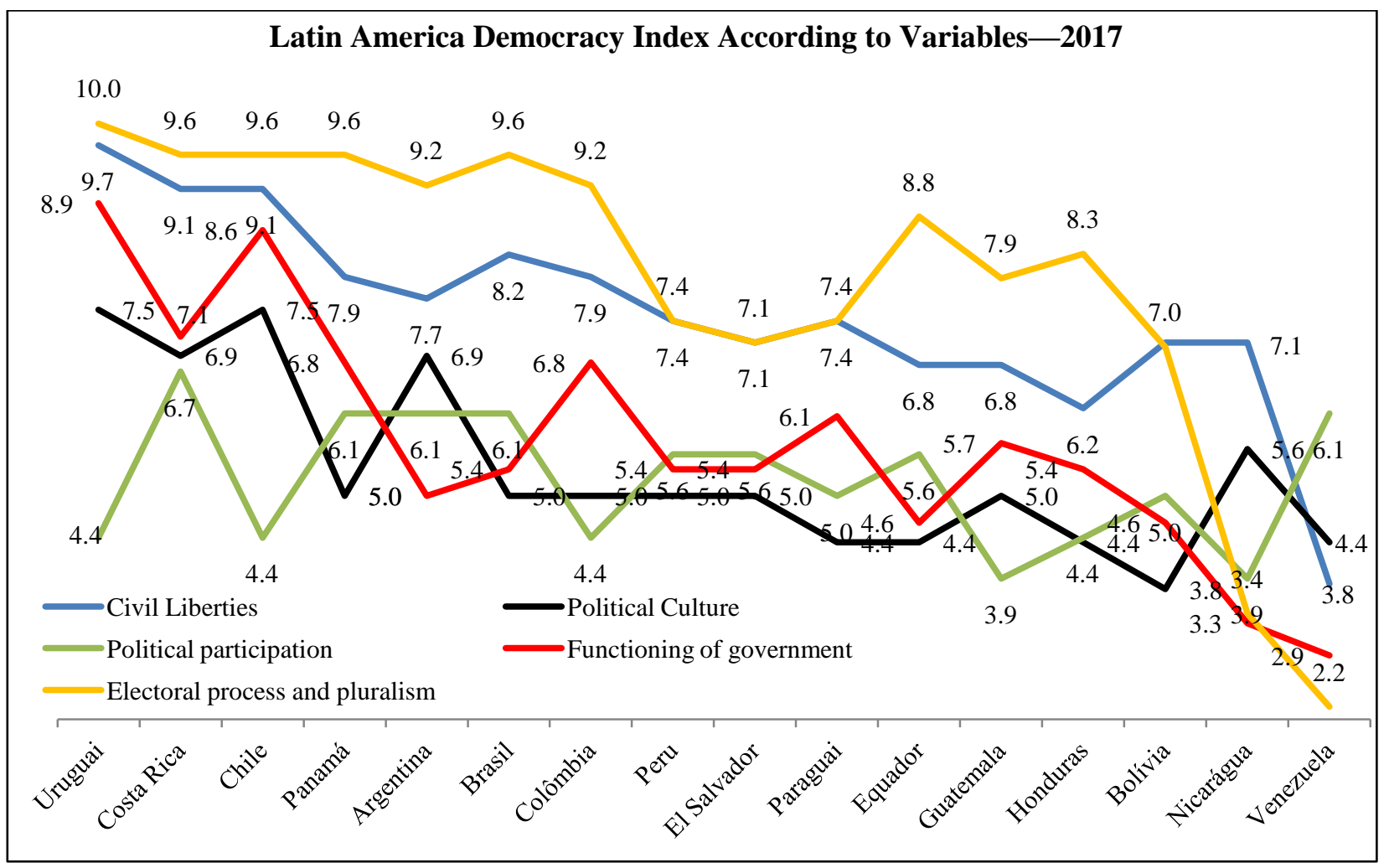

Figure 7. Latin America Democracy Index according to variables-2017. 


\section{Discussion}

The diagnosis of the democracy crisis highlights its causal factors of a multidimensional nature, among which the role of the democratic institutions stands out. The premise is that the optimum functioning of the institutions - defined by its normative justifications and by its fundamental rules of operations - has the capacity to generate the political adhesion and the trust of citizens in the democratic system in the sense that they can control not only the actions of their rulers in order to restrict abuses of power-what violates the principle of popular sovereignty, but they can also influence the decision-making process and the choices of public policies in accordance with their preferences. However, the democratic recession and its negative effects indicate that the institutions have not been operating in this sense, what makes ordinary people frustrated with the dynamics of democratic politics, puts them away from public life, and thus discourages the consolidation of a civic culture favoring the participation of citizens, through which their interests could be defended. The democratic recession aggravates the power asymmetry arising from the relations between democracy and capitalism, and makes way for criticisms to the basics of the regime, both from the left and from the right of the contemporary political scene. Is there an answer to this challenge?

Some obstacles for this are well known: The first one is the time gap between elections to choose governments, which imposes huge limits on voters' power of influence, whereas, on the other hand, ensuring a wide range of autonomy for the actions of the political elites authorized by vote to rule on behalf of all. For this reason, the vertical and horizontal accountability mechanisms - as emphasized several times by Guillermo O'Donnell, are so important, through which the popular sovereignty may become effective. Another condition, sometimes more powerful than the previous one, is the unbalance of the political competition where there are not controls on the influence of the economic power in elections. In this regard, the mechanisms restricting and limiting the funding of parties and electoral campaigns by private corporations and companies, or which provide for the allocation of taxpayers' money for such funding are decisive, upon well-defined rules of equity. However, in the absence of such mechanisms, the principle of equity in electoral competition tends to be compromised.

It is only when the dialectic game between the elites and the demos becomes strong to shape the institutional design of democracy-making the interrelation and the interinstitutional control among the different spheres of power and the different political forces effective, through parties and representation and justice institutions - that the possibility to control or eliminate the effects of power asymmetries becomes possible. However, if the performance of institutions does not indicate such possibility-as indicated in the diagnosis of the present democratic recession-democracy is at risk of losing sense and not representing an effective path for citizens to see themselves as part of the political community. In these conditions, the rule of law weakens, the political intolerance and violence - deep-rooted in conflicts of interest - take the place of understandings, commitment, and cooperation, and the episodes of anomy with their negative effects occur, poisoning the democratic environment.

Yet, the democratic politics does not rule out the transformation of such scenario. Democracy is by nature a regime liable to changes, retreats, and improvements concerning the practical application of the fundamental principles which have been defining its meaning since its inception, namely freedom and equality. Therefore, democracy should not be regarded as something that suggests a definitive end about which its success could be measured, and it should not be expected to reach a stage in which the construction of the regime would be 
deemed as completed. As the dynamics of democracy encourages the continuous emergence of new demands, which are being gradually included in the list of promises of the regime, it supposedly becomes dependent on the uncertain and unpredictable outcomes of the competition and of the power play driving political forces, and which may result both in advances and retreats of the regime. In this regard, a recent example comes from the oldest democracy on earth, created in the 18th century, which introduced limitations to fundamental rights in consequence of fights against terrorism and immigration as well.

But the alternative does not refer exclusively to the performance of the institutions; it also involves the efficacy and the quality of intervention of the different actors in politics, which, under conditions of equity of the electoral competition, can pave the way to fight the aforementioned asymmetries. According to several theorists of the democratic thought, this depends on the effectivity of the enforcement of the law, on the control of the political violence, on the separation and autonomy of the republican branches, on the honesty of the mechanisms to choose governments, on the control of the economic power in elections, on the access of citizens to justice, on the clearance of the means of political participation and, especially, on the performance of the political representation institutions, like parties and parliaments, which are in charge of making effective room for connection, influence, pressure, inspection, and control by citizens upon those holding the power.

Thus, there should be out of question that the quality of democracy depends a lot on the optimum functioning of the institutions, i.e., on how much its performance ensures the integrity of the electoral processes, the effectiveness of the accountability mechanisms - allowing for the identification, control, and punishment of those responsible for abuses of power-and the autonomy and the independence of parliaments and political parties, through which actors from different standpoints and interests can express themselves and act freely. However, this per se is insufficient to fight the democratic recession: The necessary change can take place only if, contrary to authoritarian initiatives - like left-wing and right-wing populisms - there is leading action by the democratic actors, which, possessing political and moral authority, manage to mobilize their societies to commence the transformations and the improvements necessary to overcome the crisis. The democratic recession is for sure an outcome of forces operating against democracy, but it is also the outcome of the ineffectiveness of the forces that define themselves as democratic. It is only from the action of such forces and their dialogue with their societies that the current crisis scenario may change.

It is important to recognize that such possibility has more chances of success when comprehensive paradigms or projects intending to take the place of the representative democracy are fragile, inconsistent, or do not exist, like nowadays. Indeed, today, unlike what occurred after the end of the World War II and during the Cold War, democracy has not been challenged by a consistent political and ideological model capable of threatening its qualities. However, such advantage per se does not ensure that the crisis will come to an end, and the reason of this is that - presently - the qualities and the values of democracy have been eroded from inside, from the deterioration of its performance and the loss of its meanings; hence, the crisis of democracy is also the crisis of its players. The lack and the absence of democratic leaders capable of diagnosing the nature of the crisis and mobilizing their societies to adopt innovative steps to solve it, as well as the abandonment of the values and of the civic culture that encourages and strengthens the participation of citizens, is a factor aggravating the crisis. So, the answer to the democratic recession has to come from the emergence of a new performance of the democratic leaders, which, once they manage to gather and mobilize their societies to act, will have the indispensable support to halt the recession and solve the crisis. 


\section{References}

Coppedge, M., Gerring, J., Altmanet, D., Bernhard, M., Fish, S., Hicken, A., ... Teorel, J. (2011). Conceptualizing and measuring democracy: A new approach. Perspectives on Politics, 9(2), 247-267.

Dahl, R. A. (1971). Polyarchy: Participation and opposition. New Haven/London: Yale University Press.

Dahl, R. A. (1989). Democracy and its critics. New Haven, Connecticut: Yale University Press.

Diamond, L. (2015). O Espírito da Democracia. Curitiba: Instituto de Atuação.

Diamond, L., \& Morlino, L. (2005). Assessing the quality of democracy. Baltimore: The Johns Hopkins University Press.

Fukuyama, F. (1989). The end of history? The National Interest, 16, 3-18.

Fukuyama, F. (1992). The end of history and the last man. NY: Free Press.

Huntington, S. P. (1991). The third wave: Democratization in the late twentieth century. Norman: University of Oklahoma Press.

Levitsky, S., \& Ziblatt, D. (2018). How democracies die. Cambridge, Massachusetts: Harvard University Press.

Mainwaring, S., \& Welna, C. (2003). Democratic accountability in Latin America. Oxford: Oxford University Press.

Marshall, T. H. (1967). Cidadania, Classe Social e Status. Rio de Janeiro: Zahar Editores.

Moisés, J. A. (2011). Civic culture. In B. Badie, D. Berg-Schlosser, \& L. Morlino, International encyclopedia of political science (pp. 243-248). London: Sage; IPSA.

Moisés, J. A. (2015). Quality of democracy and political inclusion. In M. Vianello \& M. Hawkesworth (Eds.), Gender and power (pp. 235-252). New York: Palgrave Macmillan.

Muller, J.-W. (2016). What is populism? E-book.

Munck, G. L. (2009). Measuring democracy. Baltimore: The Johns Hopkins University Press.

Munck, G. L., \& Mantilla, S. (2013). La Calidad de Democracia: Perspectivas desde América Latina. Quito: CELAEP y Fundación Hanns Seidel.

Norris, P. (1999). Critical citizens. New York: Oxford University Press.

O’Donnell, G. (2003). Horizontal accountability: The legal institutionalization of mistrust. In S. Mainwaring \& C. Welna (Eds.), Democratic accountability in Latin America (pp. 34-54). Oxford: Oxford University Press.

O’Donnell, G., Cullell, J. V., \& Iazzetta, O. M. (2004). The quality of democracy-Theory and applications. Notre Dame, Indiana: University of Notre Dame Press.

Pinto, A. C., Sousa, L., \& Maglhães, P. (2013). A Qualidade da Democracia em Portugal-A Visão dos Cidadãos. Lisboa: Imprensa de Ciências Sociais.

Przeworski, A. (1991). Democracy and the market. Cambridge: Cambridge University Press.

Rueschemeyer, D. (2005). Addressing inequality. In L. Diamond \& L. Morlino (Eds.), Assessing the quality of democracy (pp. 47-61). Baltimore: The Johns Hopkins University Press.

Sartori, G. (2017). O que é democracia? Curitiba: Instituto Atuação.

Schmitter, P. (2016). The future of democracy is not what it used to be. Proceedings from the Science Council of Japan, Tokyo.

Schumpter, J. A. (1961). Capitalismo, Socialismo e Democracia (Capitalism, socialism, and democracy). Rio de Janeiro: Fundo de Cultura. 